
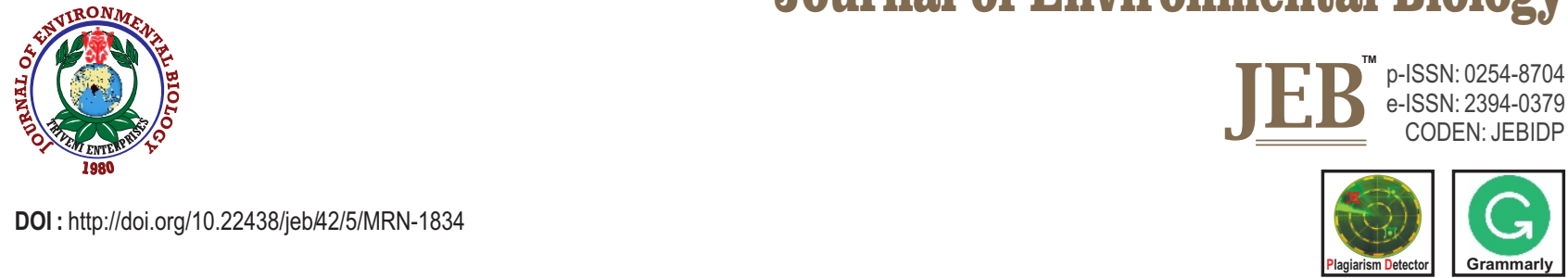

\title{
A comprehensive study of chitosan application for extending shelf life of tomato
}

\author{
M. Meena', S. Pilania ${ }^{1 *}$, K.K. Meena', S.S. Lakhawat' and V. Saharan ${ }^{3}$ \\ 'Department of Horticulture, Rajasthan College of Agriculture, Maharana Pratap University of Agriculture and Technology, Udaipur-313001, India \\ ${ }^{2}$ Department of Horticulture, SKN College of Agriculture, Sri Karan NarendraAgriculture University, Jaipur-303329, India \\ ${ }^{3}$ Department of Molecular Biology and Biotechnology, Rajasthan College of Agriculture, Maharana Pratap University of Agriculture and Technology, \\ Udaipur-313001, India
}

*Corresponding Author Email : qcishalini@gmail.com

\section{Abstract}

Aim: The aim of the present study was to study the effect of chitosan treatment on extending the shelf life of tomatoes stored at room temperature $\left(27^{\circ} \mathrm{C} \pm 2\right)$ for 21 days.

Methodology: Chitosan working formulation were prepared by dissolving chitosan in $1 \%$ glacial acetic acid to get final concentrations with adjusting $\mathrm{pH}$ above 5 with $1 \mathrm{~N} \mathrm{NaOH}$ until suspension appears as colloide. Selected tomatoes were dipped in different concentrations of chitosan $(0.01,0.04,0.08$, $0.12,0.16$ and $0.20 \%$ and water (control) for $6 \mathrm{~min}$ and kept in well ventilated paper baskets for storage at room temperature $\left(27^{\circ} \mathrm{C} \pm 2\right)$ with $55 \pm 2 \%$ relative humidity.

Results: Chitosan treated tomatoes were evaluated for different parameters related to post harvest losses. Chitosan at $0.16 \%$ effectively prevented microbial decay, physiological loss in weight, maintained the firmness and reduced the respiration rate. Chitosan treatment further decreased the loss of titratable acidity (TA), retained the total soluble solids (TSS), total sugar, ascorbic acid, reducing sugar during storage period. Chitosan effectively preserved lycopene content, inhibit polyphenol oxidase (PPO) activity, maintained $L^{*}, a^{*}, b^{*}$ value and organoleptic score during storage from day 1 to day 21 as compared to control tomatoes.

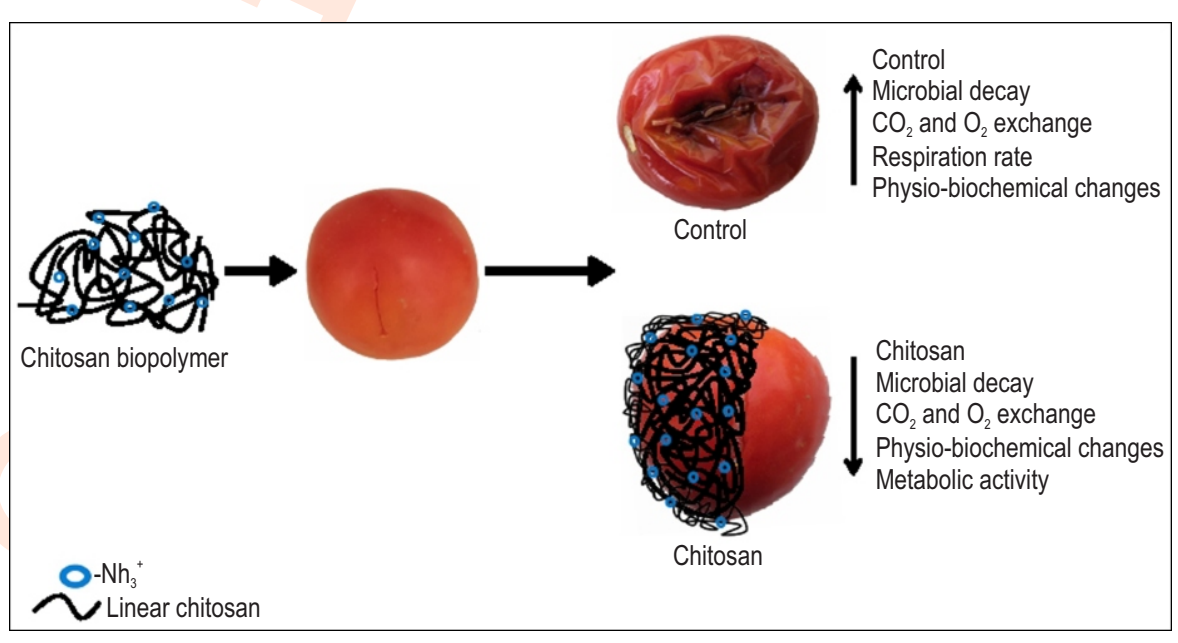

Interpretation: The study delves that low concentration of chitosan $(0.16 \%)$ effectively extend the shelf life of tomato.

Key words: Chitosan, Shelf-life, Tomatoes

How to cite : Meena, M., S. Pilania, K.K. Meena, S.S. Lakhawat and V. Saharan: A comprehensive study of chitosan application for extending shelf of tomato. J. Environ. Biol., 42, 1405-1414 (2021). 


\section{Introduction}

Tomato (Lycopersicon esculentum L.) is an most important vegetable crop containing high amount of vitamins, malic acid, citric acid and bioactive compounds like antioxidants (lycopene, ascorbic acid and $\beta$-carotene), which serves as nutrition to human diet (Khatri et al., 2020). Postharvest life of tomato fruit is limited by the rapid deterioration of physiobiochemical changes due to its climacteric nature (Candir et al., 2018). In view of the increasing demand for fresh tomatoes, it is required to maintain its color, flavor, texture and appearance, which valorize its market value and long-distance shipping. High temperature in tropical and subtropical area, climacteric fruits show high respiration rate which results in rapid ripening and corrosion of fruit quality that eventually shorten their postharvest life (Khatri et al., 2020). Currently, various methods are being used to control the post harvest losses like pre-cooling after harvest, refrigeration, control and modified atmosphere packaging and use of agrochemicals viz. hydrogen peroxide, calcium chloride, 1-methylcyclopropene (Arah et al., 2015; Sucharitha et al., 2018). The use of agrochemical has raised serious concern because of their adverse effects on human health and the environment (Dominguez et al., 2012).

Globally, the post-harvest loss of tomatos are $25-42 \%$, indicating that existing methods used for preserving tomatoes are inadequate to overcome this loss and there a need to develop new methods which are not only economical to growers but also safe for consumers and environment (Arah et al., 2015; Abera et al., 2020). Chitosan is a linear amino polysaccharide of glucosamine and $\mathrm{N}$-acetyl glucosamine units and obtained by alkaline deacetylation of chitin extracted from the exoskeleton of crustaceans such as shrimps and crabs as well from the cell walls of some fungi. Chitosan has been used by researchers to deliver eco-friendly solutions to improve the keeping quality of perishable crops like tomato (Arah et al., 2015). In this line, chitosan has been applied in different ways to extend the shelf-life of fruits and vegetables (El Ghaouth et al., 1992b; Liu et al., 2007; Badawy and Rabea, 2009; Feliziani et al., 2015; Kaya et al., 2016; Jongsri et al., 2016; Sucharitha et al., 2018; Candir et al., 2018; Khatri et al., 2020). Likewise, chitosan has been tested on few factors related to shelf life of tomato mainly at high concentration viz. 0.25 to $0.50 \%$ (Sucharitha et al., 2018), $0.3 \%$ (Migliori et al., 2017), 1 $\%$ (Liu et al., 2007) and $2 \%$ (El Ghaouth et al., 1992a; Nasreen et al., 2016; Nehar et al., 2018; Khatri et al., 2020). Application of chitosan remarkably preserve fruits and vegetables by decreasing the metabolic activities by reducing respiration rate and oxidation reactions (Nehar et al., 2018).

In earlier reports, chitosan has been tested on few factors related to shelf life of tomato mainly at high concentration viz., Physiological loss in weight (PLW), firmness, respiration rate and ascorbic acid. Moreover, few study has been performed on tomato at very high concentration (upto) $2 \%$ ) to overcome post harvest losses. All the reports reviled that treated tomatos were stored in control conditions viz. $20^{\circ} \mathrm{C}$ (El Ghaouth et al., 1992a), $25^{\circ} \mathrm{C}$ (Liu et al., 2007), $2^{\circ} \mathrm{C}$ and $25^{\circ} \mathrm{C}$ (Badawy and Rabea, 2009), $23.5^{\circ} \mathrm{C}$ (Nasreen et al., 2016), $25^{\circ} \mathrm{C}$ (Nehar et al., 2018), $6^{\circ} \mathrm{C}$ (Sucharitha et al., 2018) and $4^{\circ} \mathrm{C}$ (Khatri et al., 2020) after treatment of chitosan. Hence, there is a need to find out chitosan dose which can prevent the post harvest losses at room temperature. Keeping in view the above facts, the aim of this study was to test all major parameters related to post harvest losses and decrease the high concentration of chitosan for maintained the quality and extend the shelf life of tomato fruit at room temperature.

\section{Materials and Methods}

The present study was carried out on tomato fruits cv. Dev grown at university farm of Rajasthan College of Agriculture, MPUAT, Udaipur, India during 2018. Fresh and mature tomato fruits (light red) of uniform size, without any defects and diseases, were harvested in the month of September of 2018 in morning between 7-8 AM and used as an experimental material. Selected tomatoes were dipped in different concentrations of chitosan $(0.01,0.04,0.08,0.12,0.16$ and $0.20 \%$, w/v in water) and water (control) for $6 \mathrm{~min}$ and kept in well ventilated paper baskets for storage at room temperature $\left(27^{\circ} \mathrm{C} \pm 2\right)$ with $55 \pm 2 \%$ relative humidity. Chitosan, labeled as high $80 \% \mathrm{~N}$-deacetylation with low molecular weight $(50,000-190,000 \mathrm{Da})$ was purchased from Sigma-Aldrich, St. Louis, MO, USA. In present study, chitosan formulations were prepared by dissolving chitosan in $1 \%$ glacial acetic acid. The formulation was adjusted at pH above 5 with $1 \mathrm{~N}$ $\mathrm{NaOH}$ until suspension appeared colloidal.

Mechanical cut $(0.5 \mathrm{~cm} \times 1.0 \mathrm{~cm})$ was positioned on tomatoes for stimulation of microbial infection. Microbial decay was visually examined, considering the level of fungal growth on the tomato surface in the scale ranging from 1 to 5 , where $1=$ normal (no decay on fruit surface), $2=$ trace (up to $5 \%$ of fruit surface decayed), $3=$ slight (5-20\% of fruit surface decayed), 4 $=$ moderate $(20-50 \%$ of fruit surface decayed $)$ and $5=$ severe (>50\% of fruit surface decayed) (Babalar et al., 2007). Before treatment ( 0 day) denoted as initial weights and after treatments $(7,14$ and 21 days) as final weight were recorded. Physiological loss in weight (PLW) was expressed in percent and recorded by the difference between initial and final weight (taken on particular day) (Meng et al., 2008). Firmness was determined using Texture Analyzer (Model TA- XT Plus, Stable micro System Limited, Surrey, UK) equipped with cylinder probe of $50 \mathrm{~kg}$ load cell and heavy duty platform.

The force (Newton, $\mathrm{N}$ ) applied for rupturing the tomato fruits at $0.2 \mathrm{~cm} \mathrm{~s}-1$ speed, obtained the graphic form with distance covered in millimeters at $\mathrm{X}$-axis for each treatment. Respiration rate was determined by using head gas analyser (Checkmate 9900, PBI Dansensor Co., Denmark) at 7 day interval. Samples $(\sim 150 \mathrm{~g})$ were placed in silicon septum polythene bags and $\mathrm{CO}_{2}$ concentration was measured by inserting the equipment needle through silicon septum using the Head Space Gas Analyzer (Maftoonazad and Ramaswamy, 2005). Titrable acidity was 
determined following the method of AOAC (2012). Tomato samples were homogenized in $50 \mathrm{ml}$ distilled water and titrated against $0.1 \mathrm{~N} \mathrm{NaOH}(\mathrm{pH} 8.1$ ) using few drops of phenolphthalein indicator. Total soluble solids (\%) content in juice was determined with Pocket Refractometer (Atago, Japan) bearing the range 0$53^{\circ}$ Brix (AOAC, 2012). Total sugars were determined using anthrone reagent and reducing sugars were estimated using dinitrosalicylic acid following the method of Ranganna (1986). The amount of sugar was expressed as per cent sugar. Enzyme PPO in tomato fruit was assayed by the method of Taneja and Sachar (1974). Lycopene content was estimated following the method of Ranganna (1986). Pulp was repeatedly extracted with acetone until colourless appearance of the residue.

The extract was pooled in a separating funnel containing about $20 \mathrm{ml}$ of $5 \%$ sodium sulphate solution. The petroleum ether extract was poured into brown bottles containing $\sim 10 \mathrm{~g}$ anhydrous sodium sulphate and the absorbance was read at $503 \mathrm{~nm}$ on a spectrophotometer. Colour of tomato samples (treated and control) was measured by colorimeter (Hunter Lab Color Flex, Hunter Associates Laboratory Inc., Reston, VA, USA). Instrumental color data measurements were expressed in terms of luminosity (lightness) $L^{*}\left(L^{*}=0\right.$ for black and $L^{*}=100$ for white) and the chromaticity parameters $a^{*}$ (green $[-]$ to red $[+]$ ) and $b^{*}$ (blue [-] to yellow [+]). Overall acceptability of the samples was evaluated through the standard sensory evaluation techniques. The sensory attributes such as taste, flavour and acceptability was rated on a five point hedonic scale (9-Excellent, 7-Very good, 5-Good, 3-Fair, 1-Poor) by selected panel of judges (11 members). Statistical analysis was performed using JMP software version 12 (SAS, 2019) using Turkey Kramer HSD test. Each experiment was repeated twice wherein each treatment consisted of minimum three replicates.

\section{Results and Discussion}

The perusal of results showed that very low concentrations of chitosan, i.e., 0.08 and $0.16 \%$ chitosan significantly controlled tomato decay up to 21 days of storage at room temperature (Table 1). However, the results of the present investigation were better as compared with previous findings (El Ghaouth et al., 1992b; Liu et al., 2007; Badawy and Rabea, 2009; Feliziani et al., 2015; Kaya et al., 2016; Jongsri et al., 2016; Sucharitha et al., 2018; Candir et al., 2018; Khatri et al., 2020). Positively charged chitosan effectively degrades microbial cell wall and also boosts plant's immunity by enhancing defense enzymes activities. Various researchers have confirmed that different concentrations of chitosan can effectively control decay of strawberry, pomegranate and table grapes during storage (Gao et al., 2013; Feliziani et al., 2015; Candir et al., 2018; Hajji et al., 2018; Yin et al., 2021; Nia et al., 2021) confirming that chitosan coating can improve the keeping quality.

Physiological loss in weight (PLW) (\%), firmness (N) and respiration rate $\left(\mathrm{mg} \mathrm{CO}_{2} \mathrm{~kg}-1 \mathrm{~h}^{-1}\right)$ were measured at $0,7,14$ and 21 days of storage. Results of PLW showed significantly higher weight loss in control fruits (27.15\%) while lowest $(7.93 \%)$ in 0.16 $\%$ chitosan treated fruits (Fig. 1a). Similarly, fruit firmness also decreased during storage but with chitosan (0.01 to $0.16 \%$ ) treatment significantly maintained it as compared with control fruits (Fig. 1b). Highest firmness (32.33 N) was observed in tomato fruits treated with $0.16 \%$ chitosan. Moreover, respiration rate was increased up to 7 days of storage and then decreased in all the treatments. It was significantly decreased in $0.16 \%$ chitosan treated fruits at 21 days of storage (Fig. 1c). PLW is a primary concern during post-harvest storage of tomato. It is known as a great indicator of fruit freshness and mainly occurs as a result of water loss by transpiration and reserve carbon loss by respiration (Sogvar et al., 2016). Although application of chitosan has been made in table grape (Gao et al., 2013), sponge guard (Han et al., 2014), kiwi (Kaya et al., 2016), plum (Kumar et al., 2017), pomegranate (Candir et al., 2018) and strawberry (Hajji et al., 2018), but to our knowledge, reports are unavailable on control of PLW in tomato fruit using sole chitosan.

The control PLW, texture, colour, firmness and respiration rate, chitosan can be implicated by the fact that it acts as a semipermeable barrier for oxygen, carbon dioxide, moisture and other solutes which in turn reduces respiration, moisture loss and oxidation reactions (Maqbool et al., 2011). Reddy et al. (2000)

Table 1: Decay at room temperature of tomato treated with different concentrations of chitosan

\begin{tabular}{lllll}
\hline \multirow{2}{*}{ Treatments } & \multicolumn{3}{c}{ Decay } \\
\cline { 2 - 5 } & Day 0 & Day 7 & Day 14 & Day 21 \\
\hline Control (Water) & $0 \%$ (No decay) & $20 \%$ (at scale of 3) & $50 \%$ (at scale of 4) & $>50 \%$ (at scale of 5) \\
\hline Chitosan\% & & & \\
\hline 0.01 & $0 \%$ (No decay) & $5 \%$ (at scale of 2) & $20 \%$ (at scale of 3) & $50 \%$ (at scale of 4) \\
0.04 & $0 \%$ (No decay) & $5 \%$ (at scale of 2) & $20 \%$ (at scale of 3) & $>50 \%$ (at scale of 5) \\
0.08 & $0 \%$ (No decay) & $0 \%$ (No decay) & $0 \%$ (No decay) & $5 \%$ (at scale of 2) \\
0.12 & $0 \%$ (No decay) & $0 \%$ (No decay) & $5 \%$ (at scale of 2) & $20 \%$ (at scale of 3) \\
0.16 & $0 \%$ (No decay) & $0 \%$ (No decay) & $0 \%$ (No decay) & $5 \%$ (at scale of 2) \\
0.20 & $0 \%$ (No decay) & $5 \%$ (at scale of 2) & $50 \%$ (at scale of 4) & $>50 \%$ (at scale of 4) \\
\hline
\end{tabular}



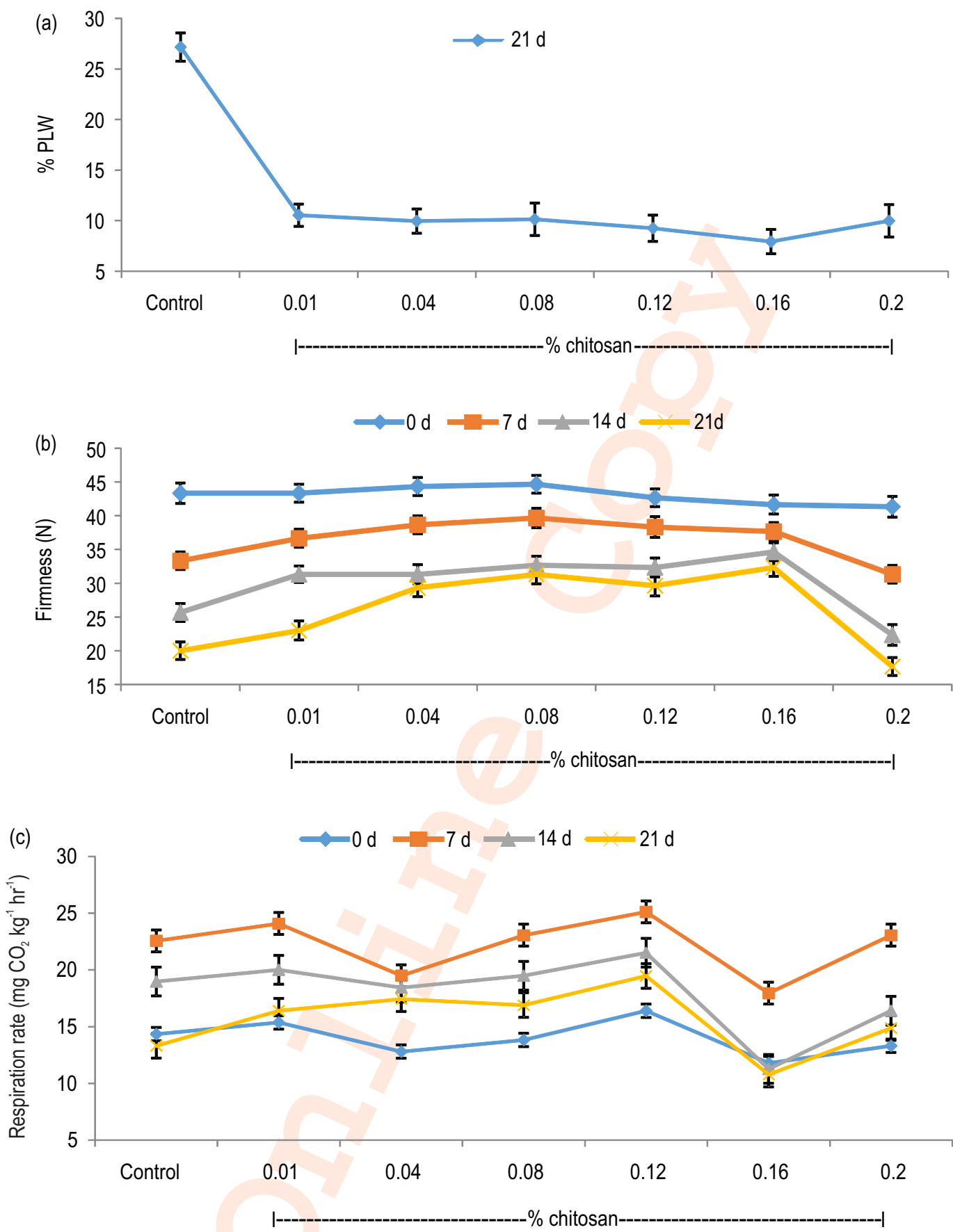

Fig. 1: Effect of different concentrations of chitosan on (a) \% PLW, (b) Firmness and (c) Respiration rate at room temperature of tomato. Each value is mean of triplicate. Error bars represents \pm SE.

reported firmness retention by chitosan may be attributed to inhibitory activity against pectate lyase, polygalacturonase and cellulase which are responsible for degradation of cell wall and subsequent loss of firmness. Moreover, suppression of respiration rate by chitosan may be due to partial blockage of pores on the surface of tomato fruit. Previous findings revealed that chitosan acts as a barrier film that creates a modified internal atmosphere by selectively permeating $\mathrm{C}_{2} \mathrm{H}_{4}, \mathrm{CO}_{2}$ and $\mathrm{O}_{2}$ in and out of fruit leading to a reduced rate of respiration and transpiration (Jitareerat et al., 2007; Ali et al., 2011). 

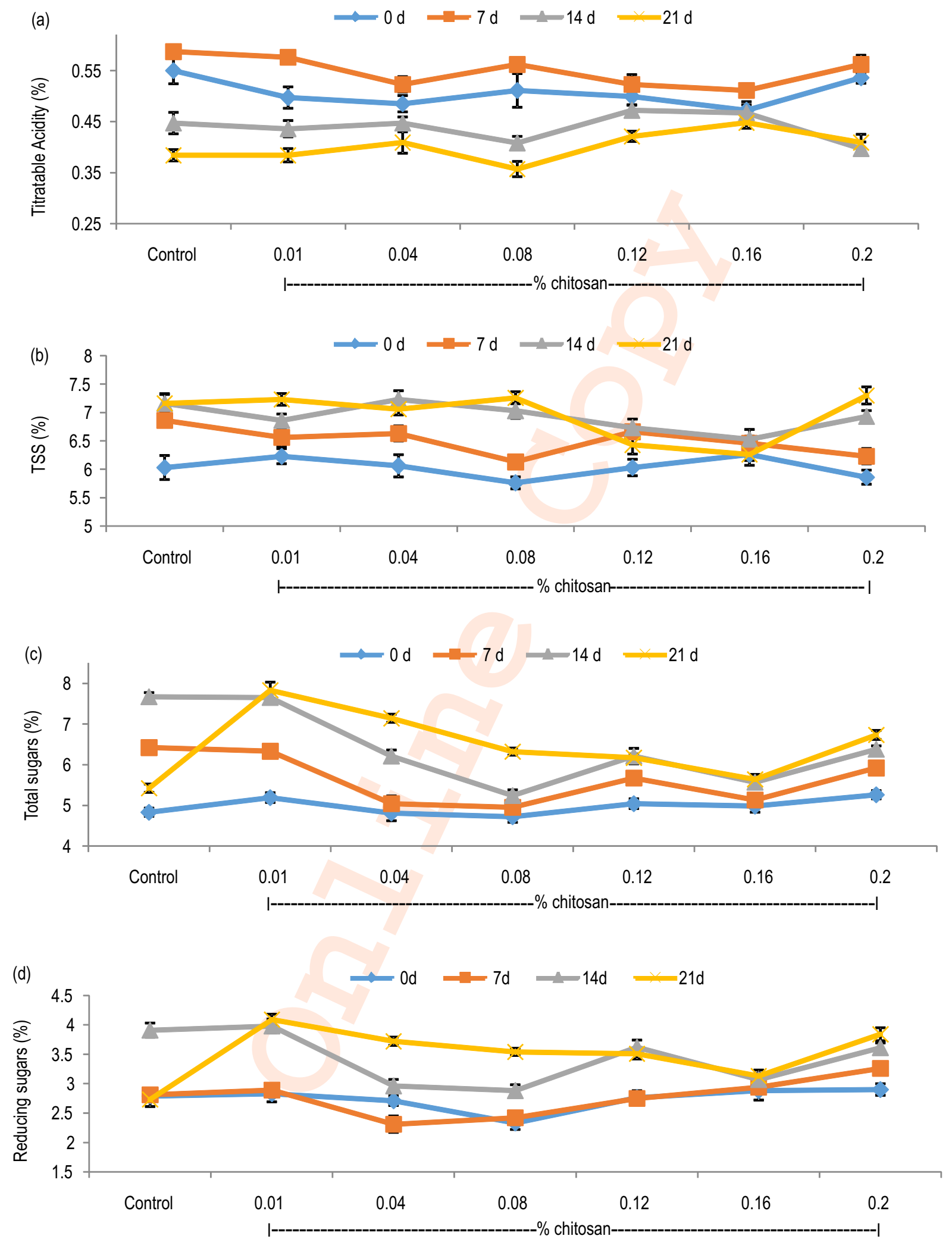

Fig. 2: Effect of different concentrations of chitosan on (a) Titratable acidity, (b) TSS, (c) Total sugars and (d) Reducing sugars at room temperature of tomato. Each value is mean of triplicate. Error bars represents \pm S.E. 


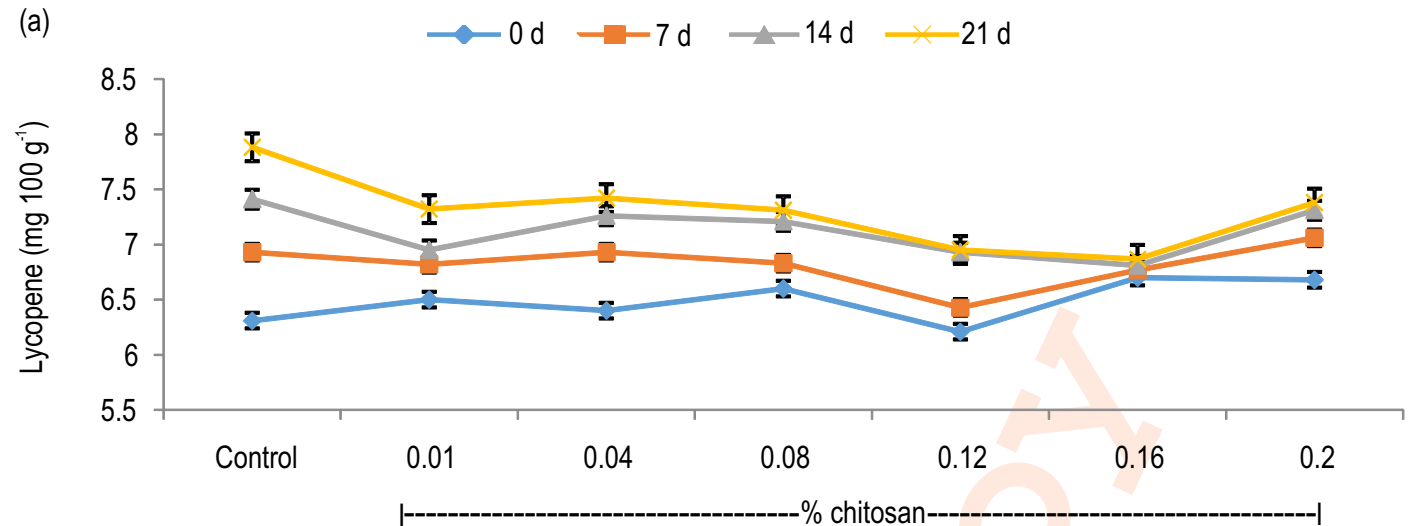

(b)

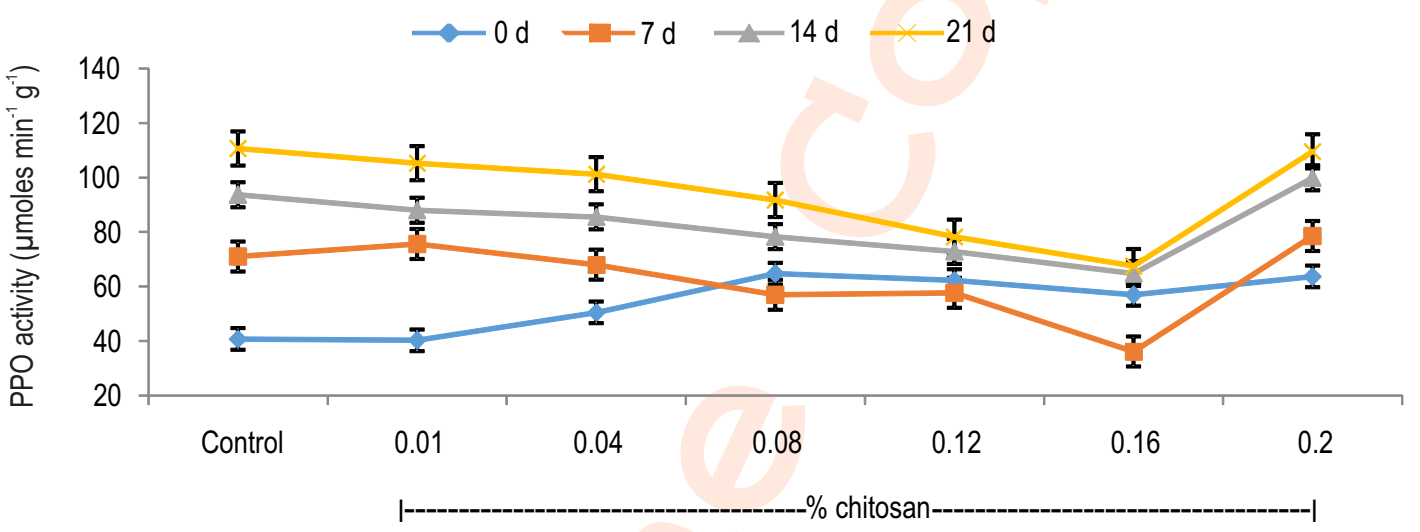

(c) $\longrightarrow 0 \mathrm{~d} \longrightarrow-7 \mathrm{~d} \longrightarrow-14 \mathrm{~d} \rightleftharpoons 21 \mathrm{~d}$

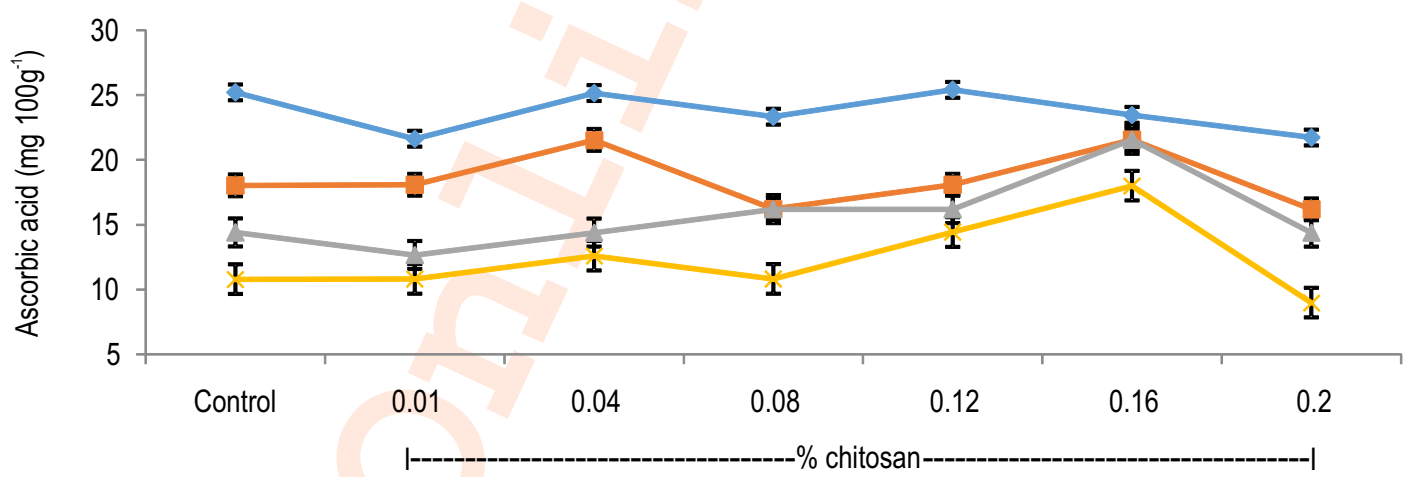

Fig. 3: Effect of different concentrations of chitosan on (a) Lycopene (b) PPO activity and (c) Ascorbic acid at room temperature of tomato. Each value is mean of triplicate. Error bars represents \pm S.E.

In present study, quality parameters showed that application of treatments significantly affected titratable acidity (TA), TSS, ascorbic acid, total sugar, reducing sugar and lycopene. Application of chitosan (0.16 \%) at 21 days of storage minimized the loss of TA in tomato fruits which was maximum in fruits treated with chitosan (Fig. 2a). Moreover, lower (6.26 \%) TSS was recorded in all the treatments of chitosan as compared with control (Fig. 2b). Further, ascorbic acid content of the fruits were significantly retain with $0.16 \%$ chitosan as compare with control fruits (Fig. 3c). However, total sugars was increased up to 

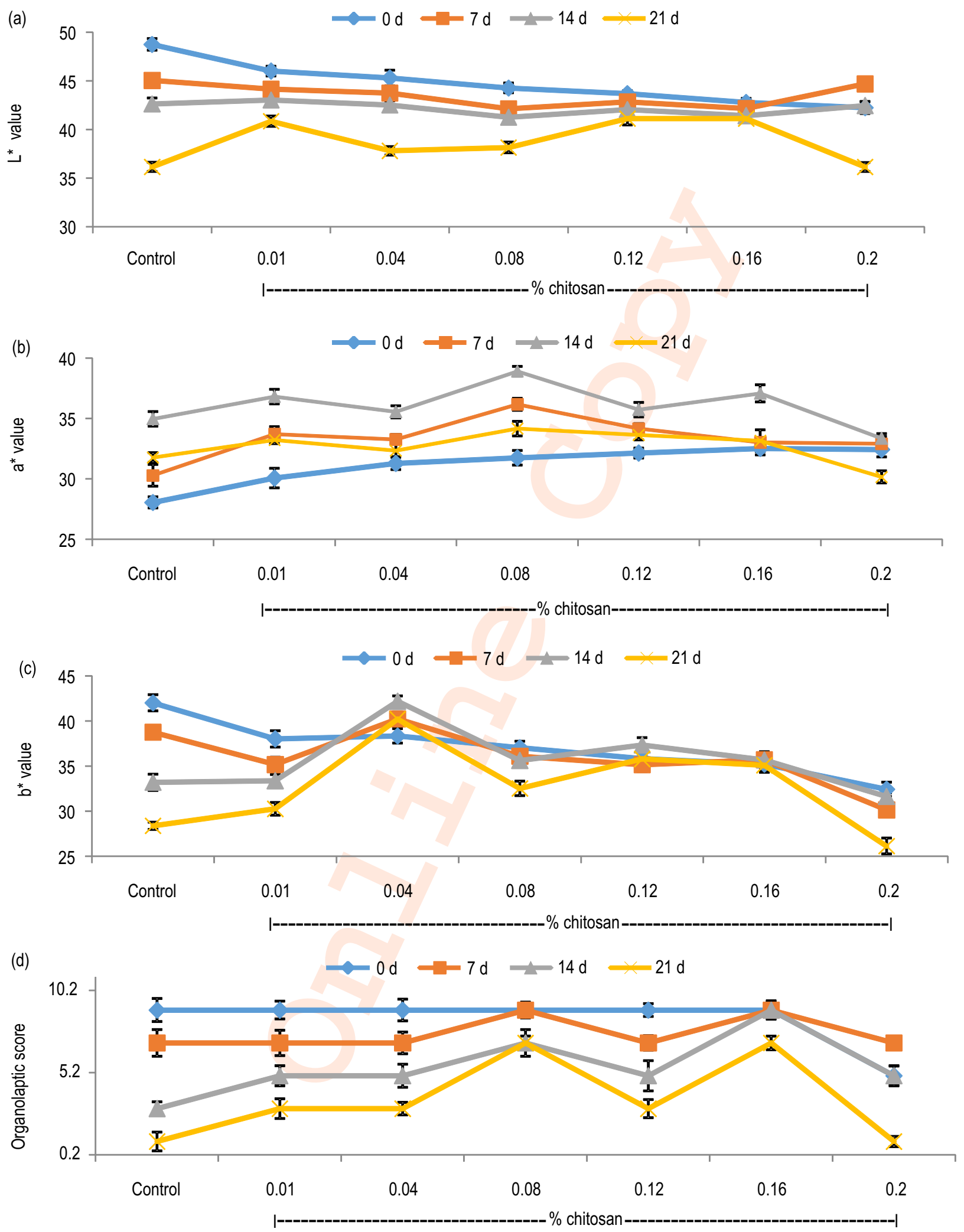

Fig. 4: Effect of different concentrations of chitosan on (a) $L^{*}$ value; (b) $a^{*}$ value; (c) $b^{*}$ value and (d) Organolaptic score at room temperature of tomato. Each value is mean of triplicate. Error bars represent \pm S.E. 
14 days and then decreased afterward. chitosan 0.08 and $0.16 \%$ significantly maintained total sugars at 14 and 21 days of storage, respectively (Fig. 2c). Similarly, $0.16 \%$ chitosan significantly delays the development of lycopene from day $1(6.70 \mathrm{mg} / 100 \mathrm{~g})$ to day 21 (6.87 mg/100g) (Fig. 3a). Previous investigation revealed that, till date there is no report on TA, ascorbic acid in tomato using chitosan further, in other fruits like table grape (Gao et al., 2013), sponge gourd (Han et al., 2014), mango (Jongsri et al., 2016), kiwi (Kaya et al., 2016), plum (Kumar et al., 2017) and strawberry (Hajji et al., 2018), chitosan effectively delayed the loss of TA during storage and significantly maintained the level of ascorbic acid. Chitosan slows down the physiological processes in tomato by reducing ethylene production, respiration and hence abbreviates the consumption of organic acids (Jongsri et al., 2016, Hajji et al., 2018, Aghofack-Nguemezi et al., 2018 and Khatri et al., 2020). It has been documented that chitosan creates a semipermeable film over fruit surface which limits fruit respiratory metabolism and thereby slows the decline of ascorbic acid (Patel et al., 2019). Starch degradation during ripening is the cause of glucose production and fruit sweetness. Generally, total and reducing sugars in tomato increase during storage periods. Reports describing the effect of chitosan on total and reducing sugars are presently unavailable. It is speculated that lamination of chitosan on tomato fruits abates gaseous exchange and lowers $\mathrm{O}_{2}$ level that reduces the metabolic activity and thus delays conversion of starch into sugars (Hong et al., 2012; Neeta et al., 2013).

The oxidative enzyme polyphenol oxidase (PPO) is responsible for the changes in color and flavor, loss of nutritional value and shelf-life of a fruit. In our study, PPO activity in tomato increased throughout the storage period in all the treated as well as untreated fruits. In control fruit, increase in PPO activity was maximum (40.73 to $110.63 \mu \mathrm{moles} / \mathrm{min} / \mathrm{g})$, but, the increase was slower in 0.01-0.16\% chitosan treated fruits (Table 4.1 and Fig. 4.1). More specifically, $0.16 \%$ chitosan significantly retarded the progression of PPO activity from 56.92 (day 1) to 67.48 umoles $\mathrm{min}^{-1} \mathrm{~g}^{-1}$ (day 21) (Fig. 3b). Badawy and Rabea (2009) earlier demonstrated that chitosan significantly inhibited PPO activity in tomato $\left(2^{\circ} \mathrm{C}\right.$ for 21 days) albeit at much higher concentration (4 $\%)$. Lycopene is principally responsible for the characteristic deep-red color of tomato fruits (Fraser et al., 1994). Markovic et al. (2006) reported that lycopene content in tomato remarkably increased from 1.82 to $11.19 \mathrm{mg} / 100 \mathrm{~g}$ during storage. Helyes et al. (2011) reported that low $\mathrm{O}_{2}$ level prevents ethylene production which decreases lycopene content in the system. It is, therefore, anticipated that bulk chitosan reduces the availability of $\mathrm{O}_{2}$ in tomato fruit which in turn inhibits the development of lycopene (Pagno etal., 2017, Khatri et al., 2020).

The hunter colour values $\left(L^{*}, a^{*}, b^{*}\right)$ decreased during storage in all the treatments as well as control. $L^{*}, a^{*}$ and $b^{*}$ values were significantly high in chitosan $(0.01$ to $0.16 \%)$ treated fruits as compared to control fruits (Fig. 4a-C). At 21 days of storage, maximum $L^{*}, a^{*}$ and $b^{*}$ values were recorded in fruits treated with $0.12 / 0.16,0.08$ and $0.04 \%$ chitosan, respectively. The results showed that $0.16 \%$ chitosan was fairly effective to preserve color, texture, flavour and overall acceptability of tomato fruit (Fig. 4d). L* (lightness), a* (red/green) and b* (blue/yellow) values are important for fruits and vegetables as colors attract the consumers. Bulk-chitosan has previously been tested for $L^{*}, a^{*}$ and $b^{*}$ values and found effective in pomegranate (Candir et al., 2018), strawberry (Feliziani et al., 2016), sponge guard (Han et al., 2014) and coffee (Barrios-Rodriguez et al., 2021). But, reports on the use of bulk- chitosan on colour aspects of tomato are lacking. Sensory evaluation is another important parameter responsible for acceptability of tomatoes by consumers. Gao et al. (2013) studied that flavor of table grape significantly decreased after 15 days of storage in untreated fruits while with chitosan treatment, the sensory parameters were maintained up to the end of storage period. Minimizing post-harvest losses in fruits and vegetables with safe, effective and economical means is a major challenge in agriculture. In this way chitosan has been found effective in preventing microbial decay as this molecule has strong antimicrobial property. In addition, chitosan in its colloidal stage acts as semi-permeable barrier for oxygen, carbon dioxide and moisture movement between food and surrounding environment (Khatri et al., 2020).

The semi-permeable coating of chitosan further controls the biochemical and other quality parameters as reported in this study. In the present study, the colloidal chitosan at low concentration highly effective in extending the shelf life of tomato which was corroborates with the previous reports (Gao et al., 2013; Feliziani et al., 2015; Candir et al., 2018; Hajji et al., 2018; Yin et al., 2021; Nia et al., 2021). In addition, biodegradable chitosan reduced the chemical load on tomato and effectively and safely increased keeping quality of tomatoes. In present results, that chitosan have comprehensively effective at low concentration $(0.16 \%)$ in preventing microbial decay, resisting the physio-biochemical changes during prolong storage and maintaining the shelf life and quality in stored tomato. Therefore, chitosan in future can be a promising eco-friendly, biodegradable and economical material for application in fruits and vegetables to prevent post harvest losses (Fisk et al., 2008; Badawy and Rabea, 2009).

\section{Acknowledgment}

Authors are thankful to the Dean, RCA, Udaipur for their kind support during the course of investigation.

\section{Add-on Information}

Authors' contribution: M. Meena: Investigation, Methodology, Formal analysis. S. Pilania: Investigation, Formal analysis, Validation, Writing - review \& editing. K.K. Meena: Project administration, Resources, Supervision, Visualization, software. S.S. Lakhawat: Project administration, Resources, Supervision, software. V. Saharan: Conceptualization, Visualization, Supervision, Project administration, Writing - original draft, Funding acquisition. 
Research content: The authors declare that there is no conflict of interest.

Ethical approval: Not applicable

Conflict of interest: Authors declare that they do not have any financial conflict of interest.

Data from other sources: Not applicable

Consent to publish: All authors agree to publish the paper in Journal of Environmental Biology.

\section{References}

Abera, G., A. M. Ibrahim, S. F. Forsido and C. G. Kuyu: Assessment on post-harvest losses of tomato (Lycopersicon esculentem Mill.) in selected districts of East Shewa Zone of Ethiopia using a commodity system analysis methodology. Heliyon, 6, e03749 (2020).

Aghofack-Nguemezi, J., T. Hoffmann and W. Schwab: Effects of biobased coatings on the ripening and quality attributes of tomato (Solanum lycopersicum) fruits. J. Sci. Food Agric., 99, 1842-1849 (2018).

Ali, A., M.T.M. Muhammad, K. Sijam and Y. Siddiqui: Effect of chitosan coatigns on the physico-chemical characteristics of Eksotika II papaya (Carica papaya L.) fruit during cold storage. Food Chem., 124, 620-626 (2011).

AOAC: Official Methods of Analysis of the Association of Official Analytical Chemists (AOAC) international. Method 932.12, Method 920.149, Method 981.12, Method 934.06, Method 923.09, $19^{\text {th }}$ Edn., AOAC International, Washington (2012).

Arah, I.K., H. Amaglo, E.K. Kumah and H. Ofori: Preharvest and postharvest factors affecting the quality and shelf life of harvested tomatoes: Amini review. Int. J. Agron., 40, 141-147 (2015).

Babalar, M., M. Asghari, A. Talaei and A. Khosroshahi: Effect of pre-and postharvest salicylic acid treatment on ethylene production, fungal decay and overall quality of Selva strawberry fruit. Food Chem., 105, 449-453 (2007).

Badawy, M.E.I. and E.I. Rabea: Potential of the biopolymer chitosan with different molecular weights to control postharvest gray mold of tomato fruit. Postharvest Biol. Technol., 51, 110-117 (2009).

Barrios-Rodríguez, Y.F., C.A.R. Reyes, J.S.T. Campos, J.G. Hernandez and J.R. Gamir: Infrared spectroscopy coupled with chemometrics in coffee post-harvest processes as complement to the sensory analysis. LWT, 145, 111304 (2021).

Candir, E., A.E. Ozdemir and M.C. Aksoy: Effects of chitosan coating and modified atmosphere packaging on postharvest quality and bioactive compounds of pomegranate fruit cv. 'Hicaznar'. Sci. Hortic., 235, 235-243 (2018).

Dominguez, I., F. Federico, P.R. Fernando, F. Rafael and I.G. Maria: Influence of preharvest application of fungicides on the postharvest quality of tomato (Solanum lycopersicum L.). Postharvest Biol. Technol., 72, 1-10 (2012).

El Ghaouth, A., J. Arul, J. Grenier and A. Asselin: Antifungal activity of chitosan on two post-harvest pathogens of strawberry fruits. Phytopathol., 82, 398-402 (1992b).

El Ghaouth, A., R. Ponnampalam, F. Castaigne and J. Arul: Chitosan coating to extend the storage life of tomatoes. Hort. Sci., 27, 10161018 (1992a).

Feliziani, E., L. Landi and G. Romanazzi: Preharvest treatments with chitosan and other alternatives to conventional fungicides to control postharvest decay of strawberry. Carbohydr. Polym., 132, 111-117 (2015).

Fisk, C.L., A.M. Silver, B.C. Strik and Y. Zhao: Postharvest quality of hardy kiwifruit (Actinidia arguta 'Ananasnaya') associated with packaging and storage conditions. Postharvest Biol. Technol., 47, 338-345 (2008).

Fraser, P.D., M.R. Truesdale, C.R. Bird, W. Schuch and P.M. Bramley: Carotenoid biosynthesis during tomato development. Plant Physiol., 105, 405-413(1994).

Gao, P., Z. Zhu and P. Zhang: Effects of chitosan-glucose complex coating on postharvest quality and shelf life of table grapes. Carbohydr. Polym., 95, 371-378 (2013).

Hagenmaier, R.D.: A comparison of ethane, ethylene and $\mathrm{CO}_{2}$ peel permeance for fruit with different coatings. Posthar. Biol. Technol., 37, 56-64 (2005)

Hajji, S., I. Younes, S. Affes, S. Boufi and M. Nasri: Optimization of the formulation of chitosan edible coating supplemented with carotenoproteins and their use for extending strawberries postharvest life. Food Hydrocoll., 83, 375-392 (2018).

Han, C., J. Zuo, Q. Wang, L. Xu, B. Zhai, Z. Wang, H. Dong and L. Gao: Effects of chitosan coating on postharvest quality and shelf life of sponge gourd (Luffa cylindrica) during storage. Sci. Hortic., 166, 1$8(2014)$

Helyes, L., A. Lugasi, E. Peli and Z. Pek: Effect of elevated $\mathrm{CO}_{2}$ on lycopene content of tomato fruits. ActaAliment., 40, 80-86 (2011).

Hong, K.Q., J.H. Xie, L.B. Zhang, D.Q. Sun and D.Q. Gong: Effects of chitosan coating on postharvest life and quality of guava ( $P$ sidium guajava L.) fruit during cold storage. Sci. Hortic., 144, 172-178 (2012).

Jitareerat, P., S. Paumchai, S. Kanlayanarat and S. Sangchote: Effect of chitosan on ripening, enzymatic activity, and disease development in mango (Mangifera indica) fruit. N.Z.J. Crop Hortic. Sci., 35, 211$218(2007)$

Jongsri, P., T. Wangsomboondee, P. Rojsitthisak and K. Seraypheap: Effect of molecular weights of chitosan coating on postharvest quality and physico-chemical characteristics of mango fruit. Food Sci. Technol., 73, 28-36 (2016).

Kaya, M., L. Cesonien, R. Daubaras, D. Leskauskaite and D. Zabulione: Chitosan coating of red kiwi fruit (Actinidia melanandra) for extending of the shelf life. Int. J. Biol. Macromol., 85, 355-360 (2016).

Khatri, D., J. Panigrahi, A. Prajapati and H. Bariya: Attributes of Aloe vera gel and chitosan treatments on the quality and biochemical traits of post-harvest tomatoes. Sci. Hortic., 259, 108837 (2020).

Kumar, P., S. Sethi, R.R. Sharma, M. Srivastav and E. Varghese: Effect of chitosan coating on postharvest life and quality of plum during storage at low temperature. Sci. Hortic., 226, 104-109 (2017).

Liu, J., S. Tian, X. Meng and Y. Xu: Effects of chitosan on control of postharvest diseases and physiological responses of tomato fruit. Postharvest Biol. Technol., 44, 300-306 (2007).

Luo, Z., X. Xu, Z. Cai and B. Yan: Effects of ethylene and 1methylcyclopropene (1 MCP) on lignification of postharvest bamboo shoot. Food Chem., 105, 521-527 (2007).

Maftoonazad, N. and H.S. Ramaswamy: Postharvest shelf life extension of avocados using methyl cellulose- based coating. LWT-Food Sci. Technol., 38, 617-624 (2005).

Maqbool, M., A. Ali, P.G. Alderson, N. Zahid and Y. Siddiqui: Effect of a novel edible composite coating based on gum arabic and chitosan on biochemical and physiological responses of banana fruit during cold storage. J. Agric. Food Chem., 59, 5474-5482 (2011).

Mariko, N., A. Hassimotto and F.M. Lajolo: Brazilian native fruits as a 
source of phenolic compounds. In: Global Food Security and Wellness. (Eds.: G.V. Barbosa-Canovas, G.M. Pastore, K. Candogan, I.G.M. Meza, S.C.S. Lannes and A. Rosenthal), Springer Science, New York, pp. 105-123 (2017).

Markovic, K., M. Hruskar and N. Vahcic: Lycopene content of tomato products and their contribution to the lycopene intake of Croatians. Nutr. Res., 26, 556-560 (2006).

Meng, X., B. Li, J. Liu and S. Tian: Physiological responses and quality attributes of table grape fruit to chitosan preharvest spray and postharvest coating during storage. Food Chem., 106, 501-508 (2008)

Miglioria, C.A., L. Salvatib, L.F.D. Cesarec, R.L. Scalzoc and M. Parisi: Effects of preharvest applications of natural antimicrobial products on tomato fruit decay and quality during long-term storage. Sci. Hortic., 222, 193-202 (2017).

Nasreen, Z., S.A. Samad and A.M.S. Chowdhury: Effect of chitosan coating on physico-mechanical properties and shelf life extension of tomato (Solanum lycopersicum). Int. Conf. Agric. Food Eng., 6 , 401-960-967-978 (2016). doi: 10.13140/RG.2.1.4741.4160

Neeta, B.G., R.P. Pooja and T.V. Ramana Rao: Improvement of quality and shelf-life of strawberries with edible coatings enriched with chitosan. Postharvest Biol. Technol., 85, 185-195 (2013).

Nehar, P., M.A. Kader, H. Roksana, M.E. Molla and A.K. Mubarak: Extension of shelf-life of tomato using irradiated chitosan and its physical and biochemical characteristics. Int. Lett. Nat. Sci., 67, 16-23 (2018).

Nia A. E., S. Taghipour and S. Siahmansour: Pre-harvest application of chitosan and postharvest Aloe vera gel coating enhances quality of table grape (Vitis vinifera L. cv. 'Yaghouti') during postharvest period. Food Chem., 347, 129012 (2021).

Pagno, C.H., Castagna, A., Trivellini, A., Mensuali-Sodi, A., Ranieri, A., Ferreira, E.A., A.D.O. Rios and S.H. Flores: The nutraceutical quality of tomato fruit during domestic storage is affected by chitosan coating. J. Food Proc. Pres., 42, e13326 (2017). doi: 10.1111/jpp. 13326.

Patel, N., S. Gantait and J. Panigrahi: Extension of postharvest shelf-life in green bell pepper (Capsicum annuum L.) using exogenous application of polyamines (spermidine and putrescine). Food Chem., 275, 681-687 (2019).

Ranganna, S.: Handbook of Analysis and Quality Control for Fruit and Vegetable Products. $2^{\text {nd }}$ Edn., Tata McGraw-Hill Publishing Co. Ltd., New Delhi, pp. 1-104 (1986).

Reddy, M.V.B., K. Belkacemi, R. Corcuff, F. Castaigne and J. Arul: Effect of preharvest chitosan sprays on post-harvest infection by Botrytis cinerea and quality of strawberry fruit. Postharvest Biol. Technol., 20,39-51 (2000)

Saharan, V., A. Mehrotra, R. Khatik, P. Rawal, S.S. Sharma and A. Pal: Synthesis of chitosan based nanoparticles and their in vitro evaluation against phytopathogenic fungi. Int. J. Biol. Macromol., 62, 677-683 (2013)

Saharan, V., G. Sharma, M. Yadav, M. K. Choudhary, S.S. Sharma, A. Pal, R. Raliya and P. Biswas: Synthesis and in vitro antifungal efficacy of $\mathrm{Cu}$-chitosan nanoparticles against pathogenic fungi of tomato. Int. J. Biol. Macromol., 75, 346-353 (2015).

SAS: JMP: User's Guide. Version 14.2. SAS Institute, Inc., Cary, NC, USA(2019).

Sogvar, O.B., M.K. Saba and A. Emamifar: Aloe vera and ascorbic acid coatings maintain postharvest quality and reduce microbial load of strawberry fruit. Posthar. Biol. Technol., 114, 29-35 (2016).

Sucharitha, K.V., A.M. Beulah and K. Ravikiran: Effect of chitosan coating on storage stability of tomatoes (Lycopersicon esculentum Mill). Int. Food Res. J., 25, 93-99 (2018).

Taneja, S.R. and C. Sachar: Stimulation of polyphenol oxidase (monophenolase) activity in wheat endosperm by gibberellic acid, cycloheximide and actinomycin D. Ptanta, 116, 133-142 (1974).

Yin, Z., R. Chu, L. Zhu, S. Li, F. Mo, D. Hu and C. Liu: Application of chitosan-based flocculants to harvest microalgal biomass for biofuel production: A review. Renew. Sustain. Energy Rev., 145, 111159 (2021).

Zhou, R., Y. Mo, Y.F. Li, Y.Y. Zhao, G.X. Zhang and Y.S. Hu: Quality and internal characteristics of huanghua pears (Pyrus pyrifolia nakai cv. Huanghua) treated with different kinds of coatings during storage. Posthar. Biol. Technol., 49, 171-179 (2008). 